\title{
Incidence and mortality of pulmonary embolism in COVID-19: a systematic review and meta-analysis
}

\author{
Shu-Chen Liao ${ }^{1,2+}$, Shih-Chieh Shao ${ }^{3,4 \dagger}$, Yih-Ting Chen ${ }^{5,6}$, Yung-Chang Chen ${ }^{7}$ and Ming-Jui Hung ${ }^{2,8,9^{*}}$
}

Keywords: Pulmonary embolism, COVID-19, Systematic review, Meta-analysis

Coronavirus disease 2019 (COVID-19) remains an increasing global pandemic, with significant morbidity and mortality. Severe complications of COVID-19 associated with coagulation changes, mainly characterized by increased D-dimer and fibrinogen levels with higher thrombosis risk, in particular pulmonary embolism (PE), have been reported recently [1]. However, the epidemiology of PE among COVID-19 patients is currently only based on small case series and retrospective studies. This systematic review and meta-analysis addresses this gap in knowledge, facilitating first-line healthcare providers' understanding of PE incidence and mortality in COVID-19.

Relevant Chinese or English language studies were identified by systematic search of EMBASE and PUBMED from inception to June 28, 2020, using the keywords "COVID19," "pulmonary embolism," "incidence," "prevalence," and "mortality" with appropriate MeSH terms, whereby the reference lists of identified studies yielded additional sources. We excluded conference abstracts, other types of publications (e.g., editorials, review articles, commentaries and treatment consensus), and studies lacking PE incidence or mortality rate reports. Two reviewers (SCL, SCS) screened the titles and abstracts for relevance, independently assessed the full texts of the screened search results, and drew up a final list of studies for inclusion through

\footnotetext{
* Correspondence: hmj1447@cgmh.org.tw

'Shu-Chen Liao and Shih-Chieh Shao contributed equally to this work. ${ }^{2}$ College of Medicine, Chang Gung University, Taoyuan, Taiwan

${ }^{8}$ Section of Cardiology, Department of Internal Medicine, Keelung Chang Gung Memorial Hospital, Keelung, Taiwan

Full list of author information is available at the end of the article
}

discussion and only after reaching full agreement. All statistical analyses were performed using MedCalc (Windows) version 15.0 (MedCalc Software, Ostend, Belgium). Incidence and mortality rates of PE in COVID-19 are represented as proportions with $95 \%$ confidence interval (CI), using the random effects model, and displayed as Forest plot. Heterogeneity among the studies was detected by Cochran $Q$ test, whereby a $p$ value $<0.10$ indicated significant heterogeneity. We assessed the proportion of variation in study estimates attributable to heterogeneity through the $I^{2}$ statistic.

We excluded 78 out of 97 articles screened: 20 studies were duplicates, 5 were irrelevant, 3 were conference abstracts, 21 were other types of publications, 28 lacked data on PE incidence or mortality, and 1 was published in French. Ultimately, our analysis included 19 articles, mostly from Europe (84\%), and we summarize their demographic data in Table 1. Overall, the incidence and mortality rate of COVID-19 patients developing PE was 15.3\% (95\%: 9.8-21.9) and 45.1\% (95\%: 22.0-69.4), respectively. Some evidence of statistical heterogeneity among the studies reporting PE incidence $\left(I^{2}: 92.0 \%, p<0.001\right)$ and mortality $\left(I^{2}: 78.6 \%, p<0.001\right)$ in COVID-19 was observed (Fig. 1).

With increasing reports of PE following COVID-19 infection, our findings indicate that nearly 2 in 10 developed PE among a total of 1835 COVID-19 patients. Immobilization, inflammation, activated coagulation, and suppressed fibrinolysis have been proposed to explain the occurrence of PE in COVID-19 patients; however, the incidence of PE in COVID-19 patients is higher than in 


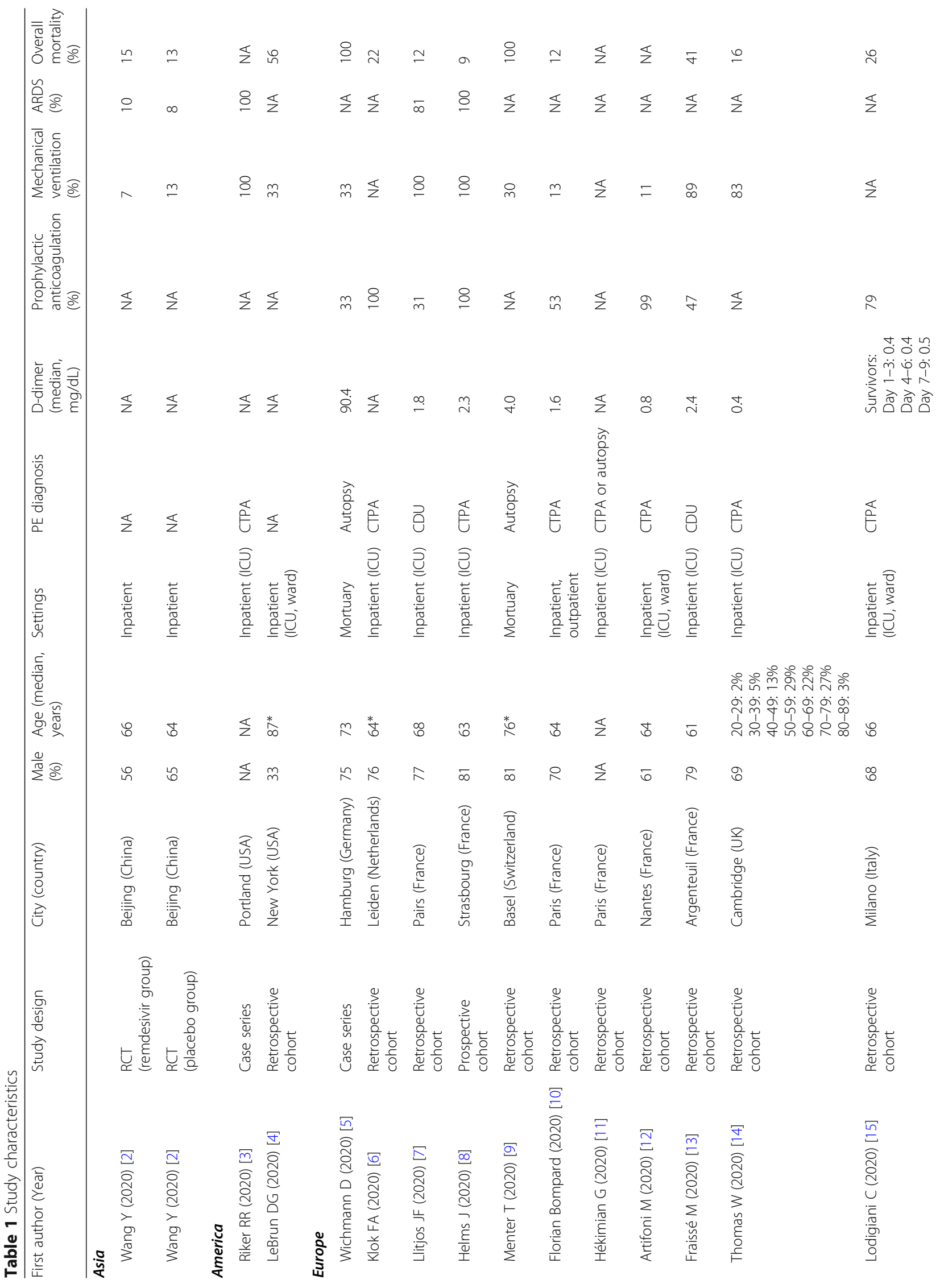




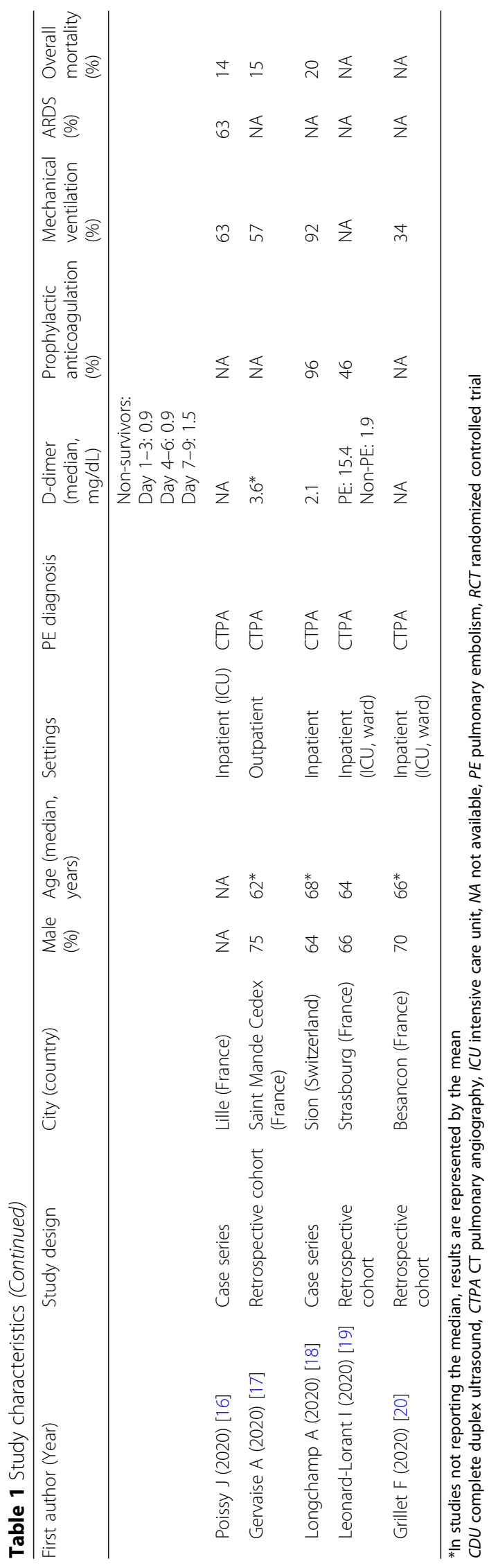




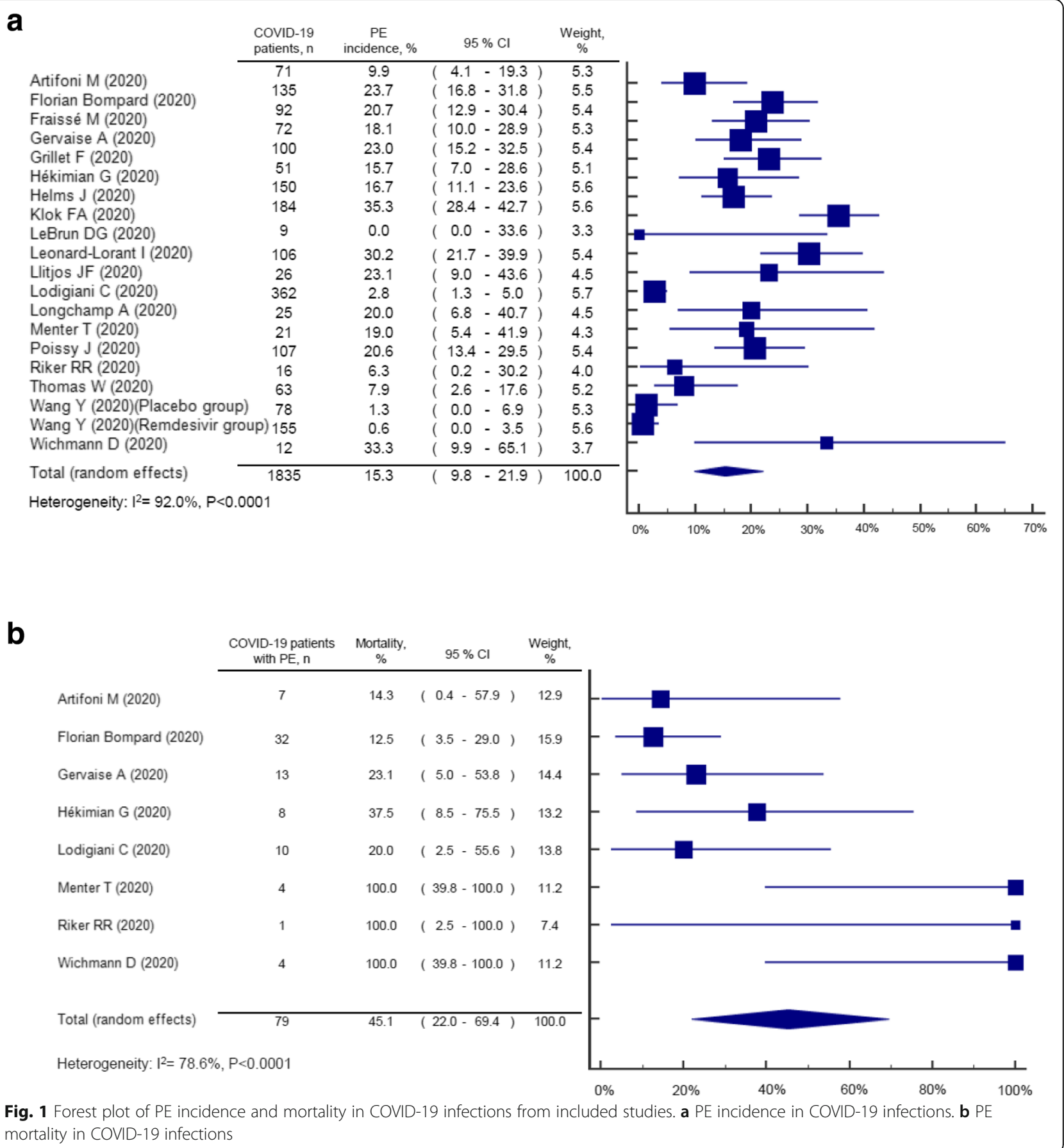

patients with seasonal and pandemic influenza (3\%) [21]. In addition, our report indicates COVID-19 patients with PE may have up to $45 \%$ higher mortality rate compared to general cases (in-hospital mortality rate 4\%) [22]. Therefore, first-line healthcare providers should be vigilant about the occurrence of severe and potentially fatal $\mathrm{PE}$ complications in COVID-19 patients [23].

As far as we know, this systematic review is the first summarizing PE incidence and mortality in COVID-19 patients. However, caution is advised in interpreting our findings. First, most published literatures are observational studies, making it difficult to confirm causality between COVID-19 and PE. Second, clinical heterogeneity between studies is noteworthy; for example, the included studies apply different diagnostic tools of varying sensitivity and specificity to investigate PE incidence. In conclusion, prevention and control of COVID-19 remains paramount in the current 
pandemic, but repeated assessment and optimal management of PE complications may significantly modify the prognosis and reduce mortality in patients with COVID-19 [24].

\section{Abbreviations}

PE: Pulmonary embolism; Cl: Confidence interval; COVID-19: Coronavirus disease 2019

\section{Acknowledgements}

None.

\section{Authors' contributions}

SCL and SCS contributed equally to this work. SCL and SCS: critical analysis, interpretation of the data, and drafting of the manuscript. MJH and YCC: study supervision and administrative, technical, or material support. All authors read and approved the final manuscript.

\section{Funding}

This research is supported by the Chang Gung Memorial Hospital Research Project CLRPG 2J0011.

\section{Availability of data and materials}

Not applicable.

\section{Ethics approval and consent to participate}

Not applicable.

\section{Consent for publication}

This original article has not been published and is not under consideration by another journal.

\section{Competing interests}

None.

\section{Author details}

'Department of Emergency Medicine, Keelung Chang Gung Memorial Hospital, Keelung, Taiwan. ${ }^{2}$ College of Medicine, Chang Gung University, Taoyuan, Taiwan. ${ }^{3}$ School of Pharmacy, Institute of Clinical Pharmacy and Pharmaceutical Sciences, College of Medicine, National Cheng Kung University, Tainan, Taiwan. ${ }^{4}$ Department of Pharmacy, Keelung Chang Gung Memorial Hospital, Keelung, Taiwan. ${ }^{5}$ Section of Nephrology, Department of Internal Medicine, Keelung Chang Gung Memorial Hospital, Keelung, Taiwan. ${ }^{6}$ School of Medicine, Institute of Public Health, National Yang Ming University, Taipei, Taiwan. ${ }^{7}$ Section of Nephrology, Department of Internal Medicine, Linkou Chang Gung Memorial Hospital, Taoyuan, Taiwan. ${ }^{8}$ Section of Cardiology, Department of Internal Medicine, Keelung Chang Gung Memorial Hospital, Keelung, Taiwan. ${ }^{9}$ Community Medicine Research Center, Keelung Chang Gung Memorial Hospital, Keelung, Taiwan.

Received: 1 July 2020 Accepted: 12 July 2020

Published online: 27 July 2020

\section{References}

1. Susen S, Tacquard CA, Godon A, Mansour A, Garrigue D, Nguyen P, et al. Prevention of thrombotic risk in hospitalized patients with COVID-19 and hemostasis monitoring. Crit Care. 2020;24(1):364.

2. Wang $Y$, Zhang D, Du G, Du R, Zhao J, Jin Y, et al. Remdesivir in adults with severe COVID-19: a randomised, double-blind, placebo-controlled, multicentre trial. Lancet. 2020;395(10236):1569-1578.

3. Riker RR, May TL, Fraser GL, Gagnon DJ, Bandara M, Zemrak WR, et al. Heparin-induced Thrombocytopenia with Thrombosis in COVID-19 Adult Respiratory Distress Syndrome. Res Pract Thromb Haemost. 2020;4:936-941.

4. LeBrun DG, Konnaris MA, Ghahramani GC, Premkumar A, DeFrancesco CJ, Gruskay JA, et al. Hip Fracture Outcomes During the COVID-19 Pandemic: Early Results From New York. J Orthop Trauma. 2020. https://doi.org/10. 1097/BOT.0000000000001849.

5. Wichmann D, Sperhake JP, Lütgehetmann M, Steurer S, Edler C, Heinemann A, et al. Autopsy Findings and Venous Thromboembolism in Patients With COVID-19. Ann Intern Med. 2020;M20-2003.
6. Klok FA, Kruip MJHA, van der Meer NJM, Arbous MS, Gommers D, Kant KM, et al. Confirmation of the high cumulative incidence of thrombotic complications in critically ill ICU patients with COVID-19: An updated analysis. Thromb Res. 2020;191:148-150.

7. Llitjos JF, Leclerc M, Chochois C, Monsallier JM, Ramakers M, Auvray M, et al. High incidence of venous thromboembolic events in anticoagulated severe COVID-19 patients. J Thromb Haemost. 2020;18(7):1743-1746.

8. Helms J, Tacquard C, Severac F, Leonard-Lorant I, Ohana M, Delabranche X, et al. High risk of thrombosis in patients with severe SARS-CoV-2 infection: a multicenter prospective cohort study. Intensive Care Med. 2020;46(6):10891098.

9. Menter T, Haslbauer JD, Nienhold R, Savic S, Deigendesch H, Frank S, et al. Postmortem examination of COVID-19 patients reveals diffuse alveolar damage with severe capillary congestion and variegated findings in lungs and other organs suggesting vascular dysfunction. Histopathology. 2020; https://doi.org/10.1111/his.14134.

10. Bompard F, Monnier H, Saab I, Tordjman M, Abdoul H, Fournier $L$, et al. Pulmonary embolism in patients with Covid-19 pneumonia. Eur Respir J. 2020;2001365

11. Hékimian $G$, Lebreton $G$, Bréchot $N$, Luyt CE, Schmidt M, Combes A. Severe pulmonary embolism in COVID-19 patients: a call for increased awareness. Crit Care. 2020;24(1):274

12. Artifoni M, Danic G, Gautier G, Gicquel P, Boutoille D, Raffi F, et al. Systematic assessment of venous thromboembolism in COVID 19 patients receiving thromboprophylaxis: incidence and role of $D$ dimer as predictive factors. Journal of Thrombosis and Thrombolysis. 2020; 50(1):211-216.

13. Fraissé $\mathrm{M}$, Logre $\mathrm{E}$, Pajot $\mathrm{O}$, Mentec $\mathrm{H}$, Plantefève $\mathrm{G}$, Contou D. Thrombotic and hemorrhagic events in critically ill COVID-19 patients: a French monocenter retrospective study. Crit Care. 2020;24(1):275.

14. Thomas W, Varley J, Johnston A, Symington E, Robinson M, Sheares K, et al. Thrombotic complications of patients admitted to intensive care with COVID-19 at a teaching hospital in the United Kingdom. Thromb Res. 2020; 191:76-77.

15. Lodigiani C, lapichino G, Carenzo L, Cecconi M, Ferrazzi P, Sebastian T, et al. Venous and arterial thromboembolic complications in COVID-19 patients admitted to an academic hospital in Milan, Italy. Thromb Res. 2020;191:9-14.

16. Poissy J, Goutay J, Caplan M, Parmentier E, Duburcq T, Lassalle F, et al. Pulmonary Embolism in Patients With COVID-19: Awareness of an increased prevalence. Circulation. 2020;142(2):184-186.

17. Gervaise A, Bouzad C, Peroux E, Helissey C. Acute pulmonary embolism in non-hospitalized COVID-19 patients referred to CTPA by emergency department. Eur Radiol. 2020;1-8.

18. Longchamp A, Longchamp J, Manzocchi-Besson S, Whiting L, Haller C, Jeanneret $S$, et al. Venous thromboembolism in critically III patients with COVID-19: Results of a screening study for deep vein thrombosis. Res Pract Thromb Haemost. 2020;4(5):842-7.

19. Leonard-Lorant I, Delabranche X, Severac F, Helms J, Pauzet C, Collange O, et al. Acute pulmonary embolism in COVID-19 patients on CT angiography and relationship to D-dimer levels. Radiology. 2020;201561.

20. Grillet F, Behr J, Calame P, Aubry S, Delabrousse E. Acute pulmonary embolism associated with COVID-19 pneumonia detected by pulmonary CT angiography. Radiology. 2020;201544.

21. Rothberg MB, Haessler SD. Complications of seasonal and pandemic influenza. Crit Care Med. 2010;38(4 Suppl):e91-7.

22. Bikdeli B, Wang Y, Jimenez D, Parikh SA, Monreal M, Goldhaber SZ, et al. Pulmonary embolism hospitalization, readmission, and mortality rates in US older adults, 1999-2015. JAMA. 2019;322(6):574-6.

23. Mojoli F, Mongodi S, Orlando A, Arisi E, Pozzi M, Civardi L, et al. Our recommendations for acute management of COVID-19. Crit Care. 2020; 24(1):207.

24. Zhai Z, Li C, Chen Y, Gerotziafas G, Zhang Z, Wan J, et al. Prevention and treatment of venous thromboembolism associated with coronavirus disease 2019 infection: a consensus statement before guidelines. Thromb Haemost. 2020;120(6):937-48.

\section{Publisher's Note}

Springer Nature remains neutral with regard to jurisdictional claims in published maps and institutional affiliations. 